\title{
A study of visceral adiposity index as a diagnostic index in gestational diabetes mellitus in a tertiary care centre
}

\author{
Padmalatha Dakshnamurthy ${ }^{1 *}$, Shaanthy Gunasingh Thangiah Kasirajan ${ }^{1}$, \\ Indhumathi Nachiyar ${ }^{1}$, Mangala Geetha ${ }^{2}$, Kannan Rajendran ${ }^{3}$
}

\begin{abstract}
${ }^{1}$ Department of Obstetrics and Gynecology, Government Kilpauk Medical College Hospital, Kilpauk, Chennai, Tamil Nadu, India

${ }^{2}$ Department of Obstetrics and Gynecology, Thoothukudi Medical College, Thoothukudi, Tamil Nadu, India

${ }^{3}$ Department of General Medicine, Saveetha Medical College, Saveetha University, Thandalam, Chennai, Tamil Nadu, India
\end{abstract}

Received: 25 January 2017

Revised: 26 January 2017

Accepted: 14 February 2017

\section{*Correspondence: \\ Dr. Padmalatha Dakshnamurthy, \\ E-mail: endork@yahoo.com}

Copyright: ( $)$ the author(s), publisher and licensee Medip Academy. This is an open-access article distributed under the terms of the Creative Commons Attribution Non-Commercial License, which permits unrestricted non-commercial use, distribution, and reproduction in any medium, provided the original work is properly cited.

\begin{abstract}
Background: Gestational Diabetes Mellitus is an emerging problem which affects pregnant women all over the world particularly in India. Early detection reduces adverse maternal and foetal outcome. Elevated central adiposity is a modifiable risk factor for abnormal glucose homeostasis in pregnancy and GDM. The Visceral Adiposity Index (VAI) is a gender-specific index of fat distribution and assessment.

Methods: It is a hospital based, case control study among the subjects who attended a tertiary care centre. cases were 30 pregnant women newly diagnosed with GDM in their 2nd trimester, and Controls were 30 apparently healthy pregnant women in their 2nd trimester without risk factors for GDM such as obesity and family history for diabetes. Visceral Adiposity Index (VAI) was calculated using the formula (Waist circumference (WC)/ $\{36.58+(1.89 \times \mathrm{xMI})\}$ ) $\mathrm{x}(\mathrm{TGL} / 0.81) \mathrm{x}(1.52 / \mathrm{HDL})$ where WC is expressed in $\mathrm{cm}, \mathrm{BMI}$ in $\mathrm{Kg} / \mathrm{m} 2$, TG in $\mathrm{mmol} / \mathrm{L}$, HDL in $\mathrm{mmol} / \mathrm{L}$.

Results: The mean age of patients with GDM was higher when compared to controls $(28.17 \pm 3.34 \mathrm{vs} 24.40 \pm 3.07)$ and this difference was statistically significant ( $\mathrm{p}$ value $<0.0001$ ). The average weights were significantly different. The mean Body Mass Index (BMI) and waist circumference (WC) was $23.59 \pm 4.19$ and $88.46 \pm 7.10$ respectively among controls and $29.85 \pm 4.52$ and $102.12 \pm 6.96$ respectively among GDM patients and these differences were highly significant $(\mathrm{p}$ value $<0.0001)$. The lipid profile of these patients showed a significantly higher value of Triglycerides among patients.

Conclusions: This study correlates GDM with Visceral adiposity index and found that the index to be elevated in the GDM group. The increased VAI in GDM patients shows their elevated adipose tissue distribution. VAI is less invasive and cost effective, can be used as a diagnostic index in GDM.
\end{abstract}

Keywords: Body mass index, Gestational Diabetes Mellitus, Triglycerides, Visceral adiposity index

\section{INTRODUCTION}

Gestational Diabetes Mellitus (GDM) affects up to $15 \%$ of pregnant women worldwide and an estimated 4 million women in India. ${ }^{1}$ Early detection and initiation of treatment reduces adverse maternal and foetal outcomes. ${ }^{2}$ Most of the pregnancies that develop GDM is associated with dyslipidemia, the assessment of which in the 2nd trimester could serve as a potential diagnostic tool. Pregnant women destined to develop GDM had higher total cholesterol, LDL, triglycerides, CRP, and t-PA but 
lower levels of HDL and adiponectin. ${ }^{3}$ Risk factors for GDM include greater maternal age, higher BMI, polyhydraminos, past history of GDM, macrosomia in previous pregnancy, history of unexplained stillbirth, type 2 diabetes mellitus in a first degree relative, polycystic ovary syndrome, etc. ${ }^{4}$ In addition, obesity is an independent risk factor for GDM, and the risk of GDM rises with an increase in the prepregnancy body mass index $(\mathrm{p}-\mathrm{BMI}) .^{5}$ It is critical to know the risk factors for GDM to allow early identification of women at risk and prevention of associated pregnancy complications.

Elevated central adiposity in early pregnancy is a modifiable risk factor for abnormal glucose homeostasis in the second trimester of pregnancy. ${ }^{6}$ Epidemiological studies show that centrally located visceral fat is more pathogenic, associated with adverse metabolic consequences than subcutaneous adipose tissue. ${ }^{7}$ High maternal visceral adiposity is associated with GDM. The Visceral Adiposity Index (VAI) is a gender-specific index, based on simple anthropometric (BMI and WC) and functional parameters like triglycerides (TGs) and high-density lipoprotein cholesterol (HDL-C) and indicative of fat distribution and function.

According to Reaven, insulin resistance is a fundamental disorder associated with metabolic abnormalities like high-TGs)/low (HDL-C) dyslipidemia. ${ }^{8}$ Since the measurement of insulin resistance clinically is impractical, the use of risk markers like VAI can predict predisposition to such metabolic disturbances.

Visceral adiposity may better predict the onset of type 2 diabetes, independent of BMI and since GDM and type 2 diabetes share the same risk factors. ${ }^{9,10}$ VAI may be an easy tool for the evaluation of adipose tissue dysfunction in various patient populations, in the absence of an overt metabolic syndrome. ${ }^{11}$ This study attempts to look for association of VAI with oral glucose intolerance in GDM.

\section{METHODS}

This study was carried out as a hospital based case control study among the subjects who attended a tertiary care hospital. Before the start of the study permission and acceptance were obtained from the institutional Scientific Research Board (SRB), Institutional Ethics Committee (IEC) and the informed consent was obtained in participant's native language prior to the commencement of study.

The study population is as follows: Cases: 30 pregnant women newly diagnosed with GDM in their 2nd trimester, Controls: 30 apparently healthy pregnant women in their 2nd trimester without risk factors for GDM such as obesity and family history for diabetes. The Inclusion criteria was Pregnant women newly diagnosed with GDM in their 2nd trimester. The exclusion criteria were multiple gestation, controls with risk factors for GDM like obesity and family history of DM were excluded from the study.

Data collection was done using standardized proforma, all the biochemical analyses were performed using automated (alpha-IMMUCHEM) and semi-automated (MERCK) clinical chemistry analyzer. All biochemical analyses were done with adequate internal quality checks, and within run and between run $\mathrm{CV}$ (coefficient of variations) was maintained.

All anthropometric measurements were done using a plastic measuring tape. Anthropometric measurement of BMI was calculated after measuring the height in metres and weight in kilograms using the formula:

$\mathrm{BMI}=$ weight in $\mathrm{kg} / \mathrm{height}$ in $\mathrm{m}^{2}$.

The waist circumference was measured using measuring tape at narrowest point between lower border of lowest ribs and iliac crest at the level of umbilicus, at the end of quiet inspiration with both feet touching and arms hanging freely.

Visceral Adiposity Index (VAI) was calculated using the formula

[Waist circumference $(\mathrm{WC}) /\{36.58+(1.89 \times \mathrm{xMI})\}] \quad \mathrm{x}$ (TGL/0.81) x (1.52/HDL) (2)

where,

WC is expressed in $\mathrm{cm}$,

BMI in $\mathrm{Kg} / \mathrm{m}^{2}$,

$\mathrm{TG}$ in $\mathrm{mmol} / \mathrm{L}$,

$\mathrm{HDL}$ in $\mathrm{mmol} / \mathrm{L}$

The collected data was entered in MS-Excel and statistical analysis will be performed using SPSS20 package.

\section{RESULTS}

This case-control study was conducted in the Department of Obstetrics and Gynaecology with 30 individuals in each group matched for gestational age, in an attempt to find the correlation of VAI with glucose intolerance in GDM.

VAI was derived from observation in a healthy normal to overweight population of a linear relationship between BMI and WC, from which a linear equation was extrapolated.

A model of adipose distribution (MOAD) was created based on this linear equation which showed a strong correlation with visceral fat mass determined by MRI. Subsequently MOAD was corrected for triglyceride and HDL cholesterol levels, thus deriving VAI. 
The exclusion criteria for cases were multiple pregnancy, which could alter the waist circumference and may interfere in assessing the increase in visceral adiposity induced by insulin resistance. Controls with risk factors for GDM like obesity and family history of DM were excluded in order to establish a valid relation of statistical significance in the TGL and HDL levels of cases and controls. For the same, the groups were matched by gestational age to avoid trimesteric changes in anthropometric measurements and physiological hyperlipidemi. The baseline characteristics of the study population is given in Table 1 .

Table 1: Baseline characteristics of the study population.

\begin{tabular}{|l|l|l|l|}
\hline Age & Cases & Control & P value \\
\hline $\begin{array}{l}\text { Gestational } \\
\text { age }\end{array}$ & $19.70 \pm 3.13$ & $20.27 \pm 2.84$ & 0.4657 \\
\hline GCT & $161.63 \pm 39.07$ & $92.50 \pm 12.41$ & $<0.0001$ \\
\hline Height & $153.37 \pm 5.07$ & $153.40 \pm 5.49$ & 0.9806 \\
\hline Weight & $70.02 \pm 9.62$ & $55.47 \pm 9.85$ & $<0.0001$ \\
\hline BMI & $29.85 \pm 4.53$ & $23.59 \pm 4.19$ & $<0.0001$ \\
\hline $\begin{array}{l}\text { Waist } \\
\text { circumference }\end{array}$ & $102.12 \pm 6.96$ & $88.47 \pm 7.10$ & $<0.0001$ \\
\hline TGL & $2.95 \pm 1.17$ & $1.98 \pm 0.65$ & 0.0002 \\
\hline HDL & $0.72 \pm 0.31$ & $0.78 \pm 0.22$ & 0.3499 \\
\hline VAI & $9.91 \pm 5.73$ & $5.54 \pm 2.41$ & 0.0003 \\
\hline
\end{tabular}

The mean age of patients with GDM was higher when compared to controls $(28.17 \pm 3.34 \mathrm{vs} 24.40 \pm 3.07)$ and this difference was statistically significant ( $\mathrm{p}$ value < 0.0001 (Figure 1).

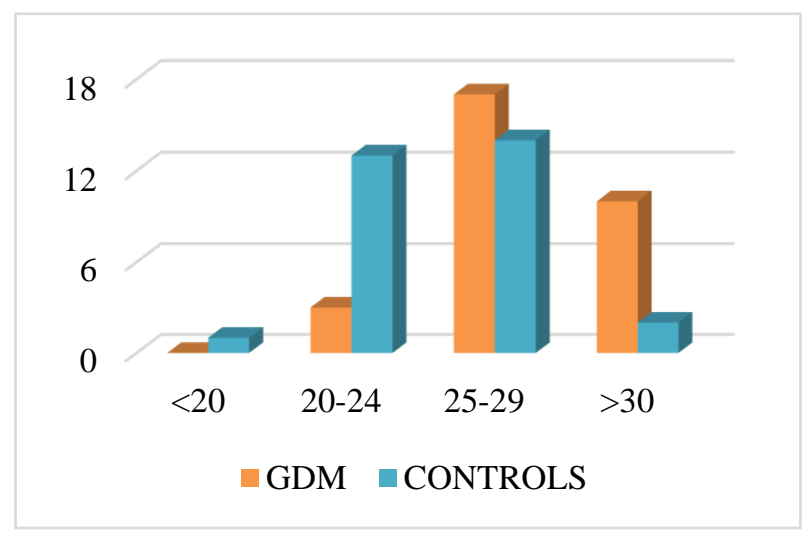

Figure 1: Age distribution.

The mean gestational age of cases and controls were comparable at baseline (Figure 2). The average height of the women was not different between the two groups but their weights were significantly different. The mean Body Mass Index (BMI) and waist circumference (WC) was $23.59 \pm 4.19$ and $88.46 \pm 7.10$ respectively among controls and $29.85 \pm 4.52$ and $102.12 \pm 6.96$ respectively among GDM patients and these differences were highly significant (p value<0.0001) (Figure 3).

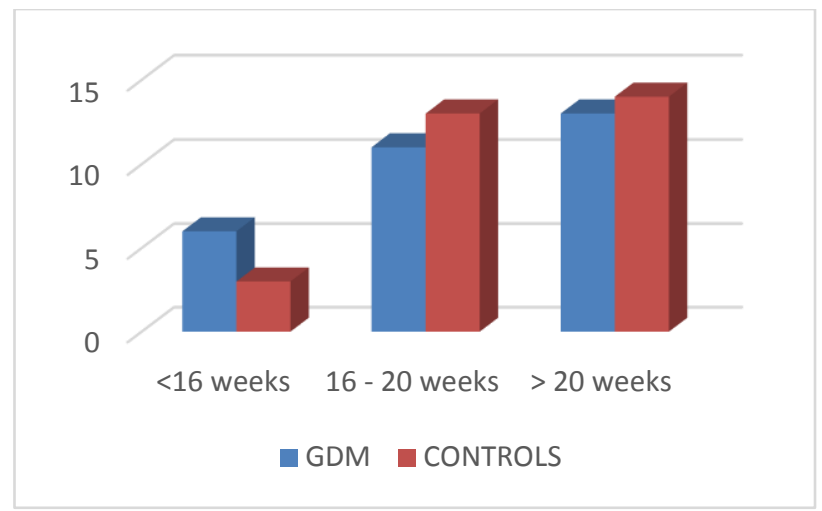

Figure 2: Gestational age distribution.

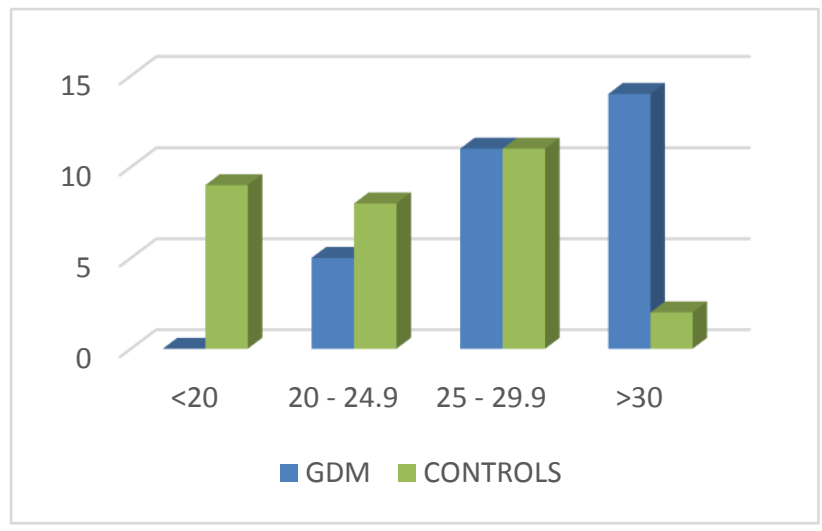

Figure 3: BMI distribution.

The lipid profile of these patients showed a significantly higher value of Triglycerides among patients while the difference in HDL-Cholesterol levels were not significant. Linear correlation analysis revealed a strong linear relation between OGCT and VAI $(\mathrm{r}=0.8322, \mathrm{R} 2=$ $0.6925, \mathrm{VAI}=0.1048 *$ OGCT $-4.019, \mathrm{p}<0.0001)($ Figure $4)$.

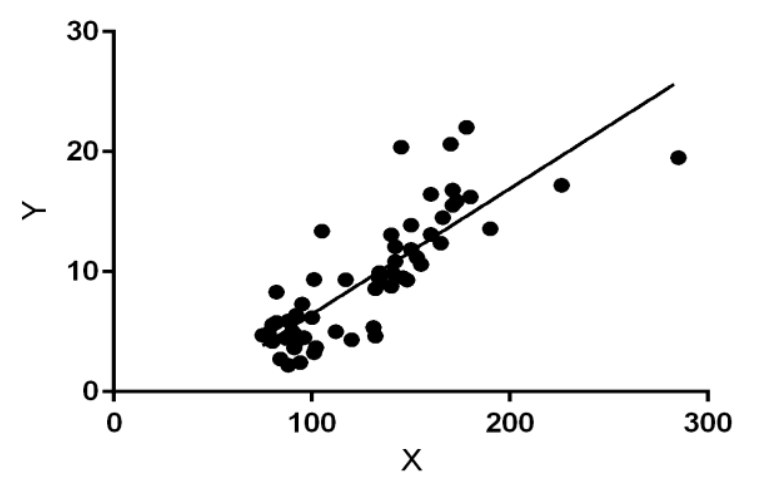

Figure 4: Linear correlation analysis between OGCT and VAI.

\section{DISCUSSION}

This study, a case control study which included 30 newly diagnosed GDM cases and 30 apparently healthy controls 
was conducted in our institution in an attempt to find the role of Visceral adiposity index (VAI) in Gestational diabetes mellitus (GDM)

The observed results revealed that the OGCT values of cases were significantly higher than in controls indicating glucose intolerance in the former.

The mean age of patients with GDM was higher when compared to controls and this difference was statistically significant ( $\mathrm{p}$ value $<0.0001$ ). The mean gestational age of cases and controls were comparable at baseline. The average height of the women was not different between the two groups but their weights were significantly different.

The mean Body Mass Index (BMI) and waist circumference (WC) among controls and GDM patients were highly significant ( $\mathrm{p}$ value $<0.0001$ ). Our finding concurs with the study done by De Souza et al where BMI and waist circumference was found to be significantly higher in cases than in controls. ${ }^{12}$

The lipid profile of the study population showed a significantly higher value of Triglycerides among patients while the difference in HDL - Cholesterol levels were not significant. TGL values in cases was significantly higher than in controls, thus proving the exaggerated hypertriglyceridaemia found throughout, in diabetic pregnancy studies by Hollisworth et al and Kokkou et al13 compared to normal pregnancy. There are also studies where no change in plasma TGL levels were found in diabetic compared to non-diabetic pregnant women. ${ }^{13-16}$

Dyslipidemia as the cause of insulin resistance in GDM is still debated as questioned by Helen et al. Though HDL levels were statistically insignificant in cases, an increasing trend towards the controls was observed which may be clinically significant. This lack of statistical significance can be substantiated based on the physiological drop in HDL levels in controls as shown in a population based study by Raghuram Pusukuru et al. ${ }^{17-}$ 18

Linear correlation analysis revealed a strong linear relation between OGCT and VAI ( $\mathrm{p}<0.0001)$. VAI was significantly higher in cases compared to controls in parallel with increase in TGL, BMI, waist circumference and decrease in HDL in cases.

However VAI has its own limitations in the presence of morbid obesity, pendulous abdomen, severe hypertriglyceridemia and/or or use of fibrates because of the extreme variations in some variables like TGL, BMI and WC.

A study by Kumpatla et al in the Indian population showed a cut-off value of VAI $\geq 2.3$ to detect glucose intolerance but in a study by Amato et al, cut off of VAI was 2.52 in a Caucasian Silican population for age group $<30$ years. Thus, Visceral adiposity index can be used as a diagnostic index for GDM. ${ }^{19-20}$ In future we need large scale studies which includes various ethnic groups correlating maternal lipid levels and GDM can be studied to understand the VAI

\section{CONCLUSION}

This study correlates the glucose intolerance in GDM with Visceral adiposity index (VAI) and found that the index to be elevated in the GDM group than in the control group. The increased VAI in GDM patients shows their elevated adipose tissue distribution. VAI which involves simple anthropometric measurements, lipid profile which is less invasive and cost effective, can be used as a diagnostic index in GDMl.

\section{Funding: No funding sources}

Conflict of interest: None declared

Ethical approval: The study was approved by the Institutional Ethics Committee

\section{REFERENCES}

1. Rajput R, Yadav Y, Nanda S, Rajput M. Prevalence of gestational diabetes mellitus and associated risk factors at a tertiary care hospital in Haryana; Indian J Med Res. 2013:137:728-33.

2. Dornhorst A, Rossi M. Risk and prevention of type 2 diabetes in women with gestational diabetes. Diabetes Care. 1998;21:43-9.

3. Savvidou M, Nelson SM, Mahlatse Makgoba. FirstTrimester Prediction of Gestational Diabetes Mellitus: Examining the Potential of Combining Maternal Characteristics and Laboratory Measures, Diabetes. 2010:59.

4. Berger H, Crane J, Farine D. Screening for gestational diabetes mellitus. J Obstet Gynaecol Can. 2002;24(11):894-912.

5. Singh CC. Huang RW. Driggers. "The impact of prepregnancy body mass index on the risk of gestational diabetes," Journal of Maternal-Fetal and Neonatal Medicine. 2012;25(1):5-10.

6. Martin AM, Berger H, Nisenbaum R. Abdominal visceral adiposity in the first trimester predicts glucose intolerance in later pregnancy. Diabetes Care 2009;32:1308-10.

7. Pi-Sunyer FX. The epidemiology of central fat distribution in relation to disease. Nutr Rev. 2004;62:120-6.

8. Reaven GM: Banting lecture 1988. Role of insulin resistance in humandisease. Diabetes. 1988;37:15951607.

9. Bray GA, Jablonski KA, Fujimoto WY, BarrettConnor E. The Diabetes Prevention Program Research Group. Relation of central adiposity and body mass index to the development of diabetes in the Diabetes Prevention Program. Am J Clin Nutr. 2008;87:1212-18. 
10. Solomon CG, Willett WC, Carey VJ. A prospective study of pregravid determinants of gestational diabetes mellitus. JAMA. 1997;278:1078-83.

11. Amato $\mathrm{MC}$ and Giordan C. Visceral Adiposity Index: An Indicator of Adipose Tissue Dysfunction, International Journal of Endocrinology. Volume 2014.

12. De Souza LR, Kogan E, Berger H. Abdominal adiposity and insulin resistance in early pregnancy.J Obstet Gynaecol Can 2014;36:969-75.

13. Hollingsworth DR, Grundy SM. Pregnancyassociated hypertriglyceridemia in normal and diabetic women. Differences in insulin-dependent, non-insulin dependent, and gestational diabetes. Diabetes. 1982;31(12):1092-7.

14. Koukkou E, Watts GF, Lowy C. Serum lipid, lipoprotein and apolipoprotein changes in gestational diabetes mellitus: a cross-sectional and prospective study. J Clin Pathol. 1996;49(8):634-7.

15. Montelongo A, Lasuncion MA, Pallardo LF. Longitudinal study of plasma lipoproteins and hormones during pregnancy in normal and diabetic women. Diabetes 1992;41:1651-9.

16. Rizzo M, Berneis K, Altinova AE. Atherogenic lipoprotein phenotype and LDL size and subclasses in women with gestational diabetes. Diabet Med 2008;25:1406-11.

17. Helen L. Barrett, Nitert MD, McIntyre HD, and Callaway LK. Normalizing Metabolism in Diabetic Pregnancy: Is It Time to Target Lipids? Diabetes Care. 2014;37:1484-93.

18. Pusukur R, Shenoi AS, Kyada PK. Evaluation of Lipid Profile in Second and Third Trimester of Pregnancy.Journal of Clinical and Diagnostic Research. 2016;10(3):12-16.

19. Kumpatla S, Michael C, Viswanathan V. Visceral Adiposity Index and pattern of dyslipidaemia at different stages of glucose intolerance-A study from India. Diab Met Syndr: Clin Res Rev. 2012.

20. Amato MC, Giordano C, Pitrone M and Galluzzo A. Cut-off points of the visceral adiposity index (VAI) identifying a visceral adipose dysfunction associated with cardiometabolic risk in a Caucasian Sicilian population. Lipids in Health and Disease. 2011; 10:183.

Cite this article as: Padmalatha D, Shaanthy Gunasingh T K, Indhumathi N, Mangala G, Kannan R. A study of visceral adiposity index as a diagnostic index in gestational diabetes mellitus in a tertiary care centre. Int J Reprod Contracept Obstet Gynecol 2017;6:1561-5. 